\title{
La importancia de la mirada en el comportamiento artístico: identidad histórica y percepción visual*
}

\section{The importance of viewing in artistic behaviour: historical identity and visual perception}

\author{
Carmen Porta \\ Facultad de Bellas Artes, Universidad de Barcelona \\ porsal@yahoo.es
}

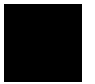

Resumen • Es evidente que hoy en día adquiere una importancia singular la visualización de imágenes y también la forma en que ellas — querámoslo o no-impactan nuestra retina, lo cual supone por parte del espectador unos criterios interpretativos que muchas veces no tiene. El presente estudio da a conocer unas pautas de lectura que, si bien nos han sido facilitadas por el análisis de la tradición, sirven de punto de partida para reflexionar sobre la obra de arte contemporánea, en este caso la pintura, desde dos puntos de vista: la propia representación pictórica y la actitud que respecto de ella tiene el propio artista.

Para ello proponemos un acercamiento al concepto percepción visual a través de un recorrido histórico que abarca desde el s. XIX hasta la actualidad, en base a la revisión de textos que nos aproximan a la obra de E. Manet, G. Braque, C. de Chirico, Z. Music, W. de Kooning, D. Hockney y G. Richter. Dicho recorrido refleja cómo una forma de ver ha dado lugar a características que marcan no solamente una manera determinada de hacer, sino también una manera peculiar de actuar por parte del artista, a la vez que provocan en el espectador una actitud distinta, en función de las coordenadas espacio-temporales referidas.

Palabras clave: ver, observador, espectador, espacio representacional, imagen, percepción visual.

Abstract • Clearly, nowadays, the visualization of images has a special meaning, as well as the way in which, voluntarily, it might or might not produce an impact in our retina. This supposes that the observer has a criteria for interpretation that is usually absent. The aim of this paper is to share reading patterns that, even though have emerged from an analysis of tradition, provide references to think about contemporary art, specially from two points of view: the first, the way we understand pictorial representations, and secondly, the attitude an artist holds towards it. We will approach the visual perception concept through a historical journey from the XIX century to our present. The analysis will review texts about the work of Manet, Braque, de Chirico, Music, de Kooning, Hockney and Richter. Our study portrays how perception has given place to characteristics that do not only belong to a particular way of behavior, but also to a peculiar form of acting by the artist which produce in the observer a different attitude in terms of the space-time references.

Keywords: viewing, observer, representational space, image, visual perception.

* Este artículo forma parte del Proyecto de Investigación en Docencia Universitaria REDICE-08, código A0801-30. 


\section{INTRODUCCIÓN}

Preguntarnos por cómo vemos significa también reflexionar sobre nuestra experiencia y nuestras propias ideas. Desatender en parte nuestros sentidos sería una forma de cerrarnos las puertas al mundo exterior. Nuestros ojos no solamente median una identificación de lo que vemos, sino que a través de ellos creamos una forma de pensar y por tanto de crear, con imágenes o con palabras, aquello que no solamente hemos visto sino también comprendido. Es por ello que la importancia del «ver», como hecho fundamental en la pintura y que merece una atención particular, ha provocado la revisión del término percepción visual desde el siglo XIX hasta hoy, tanto a partir de la voz de los propios artistas, como de la crítica del momento. Nuestro objetivo es obtener elementos de lectura que nos hablen de lo que vemos, tanto desde un punto de vista técnico como desde el comportamiento artístico que hizo posible la realización de una determinada obra de arte.

Una respuesta a ese tipo de percepciones es el lenguaje que crean los artistas en un determinado momento histórico-social y que analizamos en el presente estudio desde los siguientes puntos de vista: mirada impresionista, mirada racional, mirada surrealista, mirada distanciada y, por último, percepción en la era de la tecnología.

Si examinamos los cambios más importantes relativos a la percepción (en la tradición occidental), tenemos que hacer hincapié en al menos dos situaciones históricamente determinadas: el paso que marcó la distancia entre la imaginería medieval y el Renacimiento, y el paso entre éste y la Modernidad, época de la que, de manera sucinta, ofrecemos un recorrido por la subjetividad del observador y los procesos tanto psicológicos como fisiológicos que dieron lugar, en los siglos XIX y XX, a una nueva forma de ver. Por supuesto, habría que añadir otro cambio importante: el que vive nuestra generación, y que tiene que ver con el desarrollo de técnicas infográficas que, en los últimos diez años, ha tenido como consecuencia una relación distinta entre sujeto observador y representación. Los últimos definen la intersección de dos formas de ver que han caracterizado no sólo el espacio representacional de la pintura de final de siglo XIX y XX, sino también la actitud del ojo observador.

Esa revisión puede ser útil para posicionar al espectador frente al arte contemporáneo actual y responder a cuestiones tales como: ¿qué es lo que se ve en una pintura y qué relación guarda con su identidad histórica?, ¿cuál fue la actitud del artista para provocar tal obra de arte?, y, como consecuencia, ¿cómo ha cambiado la actitud del observador ante la misma?

\section{RESPUESTAS PERCEPTIVAS ASOCIADAS A LA REVISIÓN DE IDENTIDADES HISTÓRICAS QUE OSCILAN ENTRE EL SIGLO XIX Y NUESTRA CONTEMPORANEIDAD}

\section{MIRADA IMPRESIONISTA}

A principios del siglo XIX emerge un tipo de observador distinto que da lugar a unas condiciones que provocan el nacimiento de un nuevo tipo de lenguaje artístico. La nueva 
corriente impresionista se proclamaba en contra del arte académico, provocando la salida de los pintores desde sus talleres al aire libre y el estudio de las leyes de composición de la luz, en el marco de los nuevos avances técnicos, especialmente los referidos a la óptica. Esos aspectos se tradujeron en la práctica pictórica en la fragmentación de la pincelada o los empastes de color, aunque lo más importante no fueron las formas empleadas para resolver los temas, sino los cambios conceptuales que, referidos a una nueva forma de ver, se iban a convertir en el tema de los cuadros. En efecto, se dejan a un lado las ideas preconcebidas para interrogar directamente a la imagen. Del cuadro de Édouard Manet El ferrocarril (1872-1873) destacamos, según estudios realizados por Victor Stoichita, dos aspectos importantes. Por un lado, la percepción que del tren tiene la niña, la cual invita al espectador a situarse también dentro de la escena del cuadro, y, por otro, la imposibilidad de ver. Dichos aspectos también se pueden observar en el cuadro Boulevard des Capucines (1873) de Claude Monet. En ambos casos la representación de la luz y de la atmósfera aventaja a la de los sólidos, al tiempo que los objetos dejan de mostrarse por medio de una perspectiva lineal, para hacerlo según una perspectiva aérea y un valor tonal. De esa manera, lo que no era más que un medio, la luz, se convierte en el tema de la pintura, y los cuerpos sumergidos en esa luz y puestos unos en relación con los otros crean el «espacio».

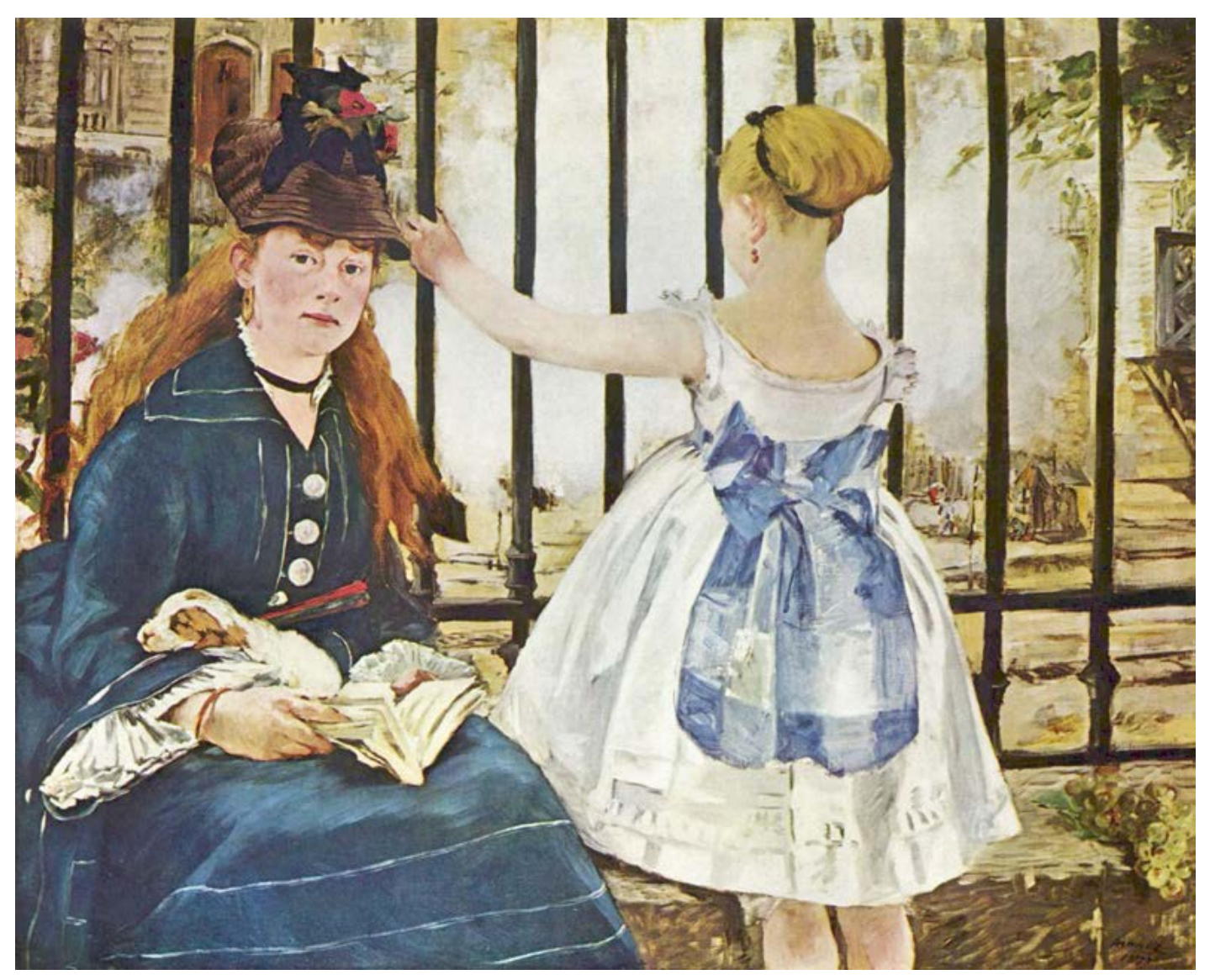

El ferrocarril, Édouard Manet (1872-1873) 
La obra de Manet El ferrocarril muestra la dificultad de mirar a través de, a la vez que abre con ello un intercambio entre lo que ocurre en el cuadro y la mirada del espectador. La dificultad de poder ver con claridad es el tema central de la obra, imposibilidad que inyecta la necesaria tensión y transfiere tal vez frustración al observador, quien se siente obligado a adoptar la actitud de la niña. Lo más importante no es tanto ya la ventana, sino el velo que conlleva; la pantalla no sólo es el soporte del cuadro sino el tema, de donde la subjetividad del artista es la que se convierte en el lenguaje pictórico. El cuadro impresionista se puede considerar entonces como fruto de la recepción subjetiva de la realidad (Stoichita, 33). Émile Zola dice al respecto, en su ensayo L'ecran de 1866:

Cualquier obra de arte es como una ventana abierta a la creación; existe en el encuadre de la ventana una especie de pantalla transparente, a través de la cual se perciben los objetos más o menos deformados, sufriendo cambios más o menos sensibles en sus líneas y en su color. Estos cambios corresponden a la naturaleza de la pantalla. No se tiene la creación exacta y real, sino la creación modificada por el medio a través del cual pasa la imagen. Vemos la creación en una obra a través de un hombre, un temperamento, una personalidad. La imagen que se produce sobre esta pantalla de nueva especie es la representación de las cosas y de las personas situadas más allá, y esta reproducción no puede ser fiel, pues cambia cada vez que una nueva pantalla viene a interponerse entre nuestro ojo y la creación [...] es seguramente difícil de caracterizar una pantalla que tiene como cualidad principal la de no existir apenas; sin embargo creo estar en lo cierto al decir que un fino polvo gris turba su limpidez, todo objeto, al atravesar este medio, pierde su brillo o, mejor, se ennegrece ligeramente (2).

La noción de transparencia velada es muy expresiva en este texto. Pantalla o velo que habla de la personalidad del artista y que es una zona a través de la cual se adivinan ciertas divergencias con la tradición, además de ofrecer al espectador acceso a una realidad distinta de aquella a la que estaba acostumbrado. Los pintores impresionistas sólo concebían la posibilidad de ser verdaderos delante del motivo, ello es, no decían de un tema más de lo que visualmente se les ofrecía. Para estudiar el mundo exterior sólo confiaban en sus sensaciones, con lo cual la subjetividad llegaba a convertirse en medio de conocimiento y la espontaneidad en característica que parecía sinónimo de veracidad. En ese contexto, vale la pena recordar las palabras de Kahnweiler, según el cual «[...] lo que Mallarmé entiende por sensación no es la sensación visual: son las emociones variadas que se incorporan a la sensación visual [...] el efecto producido por la cosa. Que el lector saque sus propias consecuencias» (200).

La reflexión sobre aquello que se ve es convertida en tema y nos permite hablar de tematización de la mirada moderna. A comienzos del siglo XIX tiene lugar algo que excede un simple cambio en las apariencia de la imagen: acompañada de transformaciones en las formas de poder institucional, se produce una reorganización del conocimiento y de las prácticas sociales, que dio como resultado un observador con un grado de independencia y poder nunca anteriormente concedido.

Se pone fin a los códigos miméticos de representación y se descubre la fotografía, la cual convivió evidentemente con artistas que interpretaban ese adelanto técnico por medio de unas formas enquistadas en una visión realista. Otros, no obstante, generaron un nuevo tipo de visión que dio efectos y significados nuevos. Experimentación e innovación iban de la mano en los años que sucedieron al siglo XIX, hasta convertirse a lo largo 
del XX en medios que, ya sea a modo de diálogo o de provocación, iban a explicar la ruptura entre la dicotomía realismo y abstracción (Crary, 20). Los avances en dispositivos ópticos y tecnológicos actuaron de intersección entre el campo de las humanidades y el científico, el arte y la ciencia formaban parte del mismo campo de juego. Si el saber permitía racionalizar a un sujeto que crecía en medio de unos valores institucionales y económicos cambiantes, posibilitaba también experimentaciones en el campo de lo visual que se traducían, al fin, en representaciones que iban a cambiar la dirección del mundo del arte. Aunque, como nos dice Gilles Deleuze, la tecnología ocupa siempre un papel subordinado: «Una sociedad se define por sus aleaciones, no por sus herramientas [...] Las herramientas existen sólo en relación a las combinaciones que hacen posibles o que las hacen posibles» (90).

\section{MIRADA RACIONAL}

La visión impresionista quería fijar la fugacidad de la naturaleza, sus cambios de luz, efectos climatológicos, instantáneas, al fin y al cabo, de color y formas un tanto pasajeras. Contrariamente a ellos, el pintor de la Provence Paul Cézanne, de temperamento obsesivo, encerrado en sí mismo y confiado hasta el extremo en sus reflexiones, fue el primero que hacia 1880 concluye con una síntesis de un nivel ciertamente inesperado, al representar la naturaleza según figuras geométricas - cono, esfera y cilindro, formas totalmente imperecederas-, construcción que marcó el mayor progreso de las leyes de la pintura moderna.

Podríamos hablar de muchos nombres que en los primeros años del siglo XX trabajan en ese marco conceptual, el cual desembocaría en la corriente que adoptó el nombre de cubismo. Metzinger y Gleizes intentaron codificar y reglamentar ese quehacer artístico. A ellos se unieron desde otros lugares geográficos artistas como Jacques Villon, André Lhote, Marcoussis, Léger y, más tarde, también Juan Gris. Braque y Picasso, a pesar de sus aportes, terminaron distanciándose. Según este último, «cuando hicimos el cubismo no teníamos intención alguna de hacer el cubismo, sino sólo la de expresar lo que había en nosotros» (Valsechi, 6). A lo que Georges Braque responde, «no se debe imitar lo que se quiere crear [...] procuro ponerme al unísono con la naturaleza [...] El arte está hecho para turbar, la ciencia tranquiliza» (Valsechi, 6).

Braque y Picasso aprendieron de la herencia cezanniana estructuras y composiciones, sin hacer nunca un abuso de ello y sin intentar tampoco convertir su práctica pictórica en una concepción que tuviera que crear escuela.

Cézanne consideró los objetos externos como el móvil de todas las ideas, pues nada hay que no proceda de la naturaleza. La necesidad de una óptica personal lo llevó a ensimismarse con el estudio de lo real, sin proponerse nunca hacer una copia. Ello habría sido poco menos que una necedad. Según decía él mismo, hay que materializar las sensaciones, leer la naturaleza es verla bajo el velo de la interpretación. Hay que ser un clásico a través de la naturaleza y por medio de la sensación, trabajando sin otra preocupación que no sea perseguir el objetivo de observar la naturaleza hasta descubrir las leyes que la rigen. 
Braque investiga de la realidad las formas que la componen. Así lo vemos en Naturaleza muerta con guitarra (1908), obra en la que recrea unos instrumentos musicales como si fueran parte de un paisaje. En su visión, la emoción por ello suscitada es lo primero, mientras que la reflexión es posterior, lo que se traduce, en este caso, en una inversión de las convenciones pictóricas, aunque con una lógica incuestionable. Comparativamente con la ya conocida frase "yo no busco, encuentro", Pablo Picasso nos sorprende con una imagen que de forma instintiva y libre de constricciones absorbe todas las experiencias acumuladas por la tradición e intuitivamente proyecta el descubrimiento de nuevas expresiones artísticas con un vigor imaginativo inigualable. No tan conocida es la frase de Georges Braque «amo la regla que corrige la emoción». Racional y lúcido, el artista, en oposición al instinto, opta por el sentido de la medida y el método cartesiano.

Las frases anteriores nos hablan de una distancia esencial entre ambos pintores: dos temperamentos, dos formas de hacer que no deben, a pesar de ello, inducirnos a error. Si bien Braque es reflexivo y su obra nace después de un proceso intelectual, en ningún caso debemos pensar que está premeditadamente construida. Braque también nos dice: «tener libre la cabeza. El concepto ciega». Con ello no hace más que hablarnos de la libertad fundamental y necesaria para que la sensibilidad intuitiva pueda expandirse sin límite. La regla que acompaña la inteligencia no sustituye la emoción, antes bien, ella resulta ser un fenómeno que tiene lugar primero y además es insustituible. Su afirmación acredita la autonomía artística por encima de cualquier otro esquema. De ahí se desprende que el acto de percibir es imprescindible desde el comienzo, tal vez de forma intuitiva, pero que no hace más que establecer una especie de filtro por llamarlo de algún modo, que traduce en imágenes aquello visto. El artista ha de trabajar sin límites que supongan una merma en su capacidad imaginativa y en su expresividad.

Si los impresionistas empleaban el sentido de la vista como instrumento fundamental, Braque y Picasso revalorizan las facultades intuitivas y autónomas de la inteligencia especulativa: «El objeto del pintor no consiste en reconstruir una anécdota, sino en constituir un hecho pictórico» (Valsechi, 6).

Además de representar aquello que veían de una forma racionalizada, los pintores mencionados intentaron abordar la imagen según sus tres dimensiones. Su mirada no era solamente puntual, sino que recorría la imagen, dando lugar a una interrelación espacio-temporal. Inversión de convenciones que el cubismo emplea para profundizar en la gestación de la que iba a ser una de las corrientes que cambiaron el rumbo del arte a principios de siglo XX.

El término tiempo implícito en sus cuadros nos trae a la memoria el componente velocidad, de donde podemos pensar en la corriente cubista como una de las precursoras de la percepción visual tal y como hasta cierto punto estamos obligados a digerir hoy. La visión contemporánea o metáfora de lo visual nos sitúa en un mundo en el que todo permanece en constante movimiento. Se trata de conceptos que hoy por hoy nos ayudan a entender lo real bajo otra perspectiva. Bauman sugiere la palabra «fluidez» para acercarnos a este tipo de comportamiento, característica asociada no al estado sólido de los cuerpos, sino a la capacidad que tiene un líquido: «Fluir chacia dónde?». Para él se trata de una pregunta sin respuesta y que ni siquiera habría que hacer. «El mismo movimiento es el propósito, nada más. La cuestión es seguir moviéndose» (60). 


\section{MIRADA SURREALISTA}

Percibir el mundo y sus formas: todas las corrientes artísticas lo han hecho de una u otra manera, pero si una de ellas descolocó nuestra forma habitual de ver fue el surrealismo. Estudiaremos las características que nos aportan estos artistas, haciendo especial mención a la obra del pintor italiano Giorgio de Chirico.

De Chirico, al menos en su primera época, interesó de forma particular a los artistas de esa corriente. En sus escritos nos habla del especial reconocimiento prestado al órgano de la vista.

Lo que oigo no vale nada. No hay más que lo que mis ojos ven cuando están abiertos y más aún cuando están cerrados, que orienta la mirada hacia lo todavía no visible, hacia la interioridad, y no hacia lo visible, la exterioridad. En este sentido, los surrealistas son continuadores de la herencia romántica: «Cierra tu ojo corporal, para que veas primero tu pintura con el ojo del espíritu», escribía C. D. Friederich en 1830. Entonces deja salir a la luz lo que viste en la oscuridad, para que pueda ejercer su efecto sobre los otros, del exterior al interior (Rubio, 65).

A lo cual André Breton responde: «Me parece que puedo exigir mucho de una facultad que, por encima de casi todas las demás me concede poder sobre lo real, sobre lo que vulgarmente se entiende como lo real» (Rubio, 65).

Ambos textos hablan por sí solos respecto a los principios básicos de dichos artistas, quienes intentaban potenciar el mundo de las sensaciones para acercarnos así a la subjetividad del individuo y situarnos delante de una mirada que no se detiene en la superficie ni tampoco en aquello reconocible exteriormente. Decía Breton que se trataba de una "mirada en estado salvaje», es decir, una mirada que observa la ingenuidad de la primera vez para descubrir paisajes nunca vistos, alejándose de toda voluntad de domesticar la visión, ya sea en base a normas o tendencias. Desde ese punto de vista se abre camino para dar posibilidad a la existencia de diferentes tipos de visión, incluso de aquello que es invisible, de aquello visto a través del recuerdo, de lo que otros dicen ver o reconocer, o de lo que nunca hasta entonces nadie se atrevió a mirar. Todo ello no es más que una invitación a penetrar en el interior de los seres y las cosas, y a descubrir lo que en ellas hay de inaccesible, como consecuencia de lo cual se propone una conquista a través del ojo de terrenos del todo desconocidos.

Poner en evidencia el mundo de las apariencias supone tanto para el pintor como para el espectador adaptar su visión a nuevos sistemas de relaciones y esquemas que sobrepasan el mundo racional. Si bien hemos hablado del reconocimiento de distintos grados de visión, también es lógico por parte de esos artistas reconocer la generación de sensaciones o estadios del ser humano distintos a los anteriormente conocidos, y de los cuales la pintura será uno de los testigos más interesantes. Aspecto que añade a la representación pictórica un valor, a la vez que se amplía su lenguaje.

Las correspondencias entre lo visual y lo pictórico le otorgan a la pintura un poder de seducción y fuerza provocativa inigualables y se considera que la pintura puede transportar la mente humana lejos de la realidad, aboliendo los límites preestablecidos. Evidentemente se estaba cuestionando lo real para entrar a conocer otras realidades no menos auténticas. Cabe mencionar la ambición de los surrealistas de transformar y cambiar el mundo, premisas que replantearon el papel del arte e invitaron a cuestionar cuál debía ser 
la práctica de la pintura en ese momento, de modo que las representaciones dejaron de ser un fin en sí mismas para devenir un medio del estado evolutivo de la sociedad.

Un cuadro supondrá, así, una realidad abierta a las profundidades del ser humano, y es más, abrirá un acceso a los orígenes que lo hicieron posible. A un lado quedan los aspectos formales, el interés se centra ahora en lo que se ve en el cuadro, para formular la pregunta de si es bello lo que desde allí se observa. La analogía del cuadro-ventana es original de los renacentistas, aunque en este caso la ventana albertiana nos habla en otro sentido. De la contemplación del espectáculo de la naturaleza concebida como un mundo exterior a nosotros, pasamos a una visión onírica, con una capacidad reveladora y misteriosa. Es por ese motivo que pensamos que, en el contexto que estudiamos, es interesante citar las aportaciones de Giorgio de Chirico, quien opta por una mirada que tiende a extrañarse delante de lo que ve y se detiene en cada cosa para desentrañar sus apariencias.

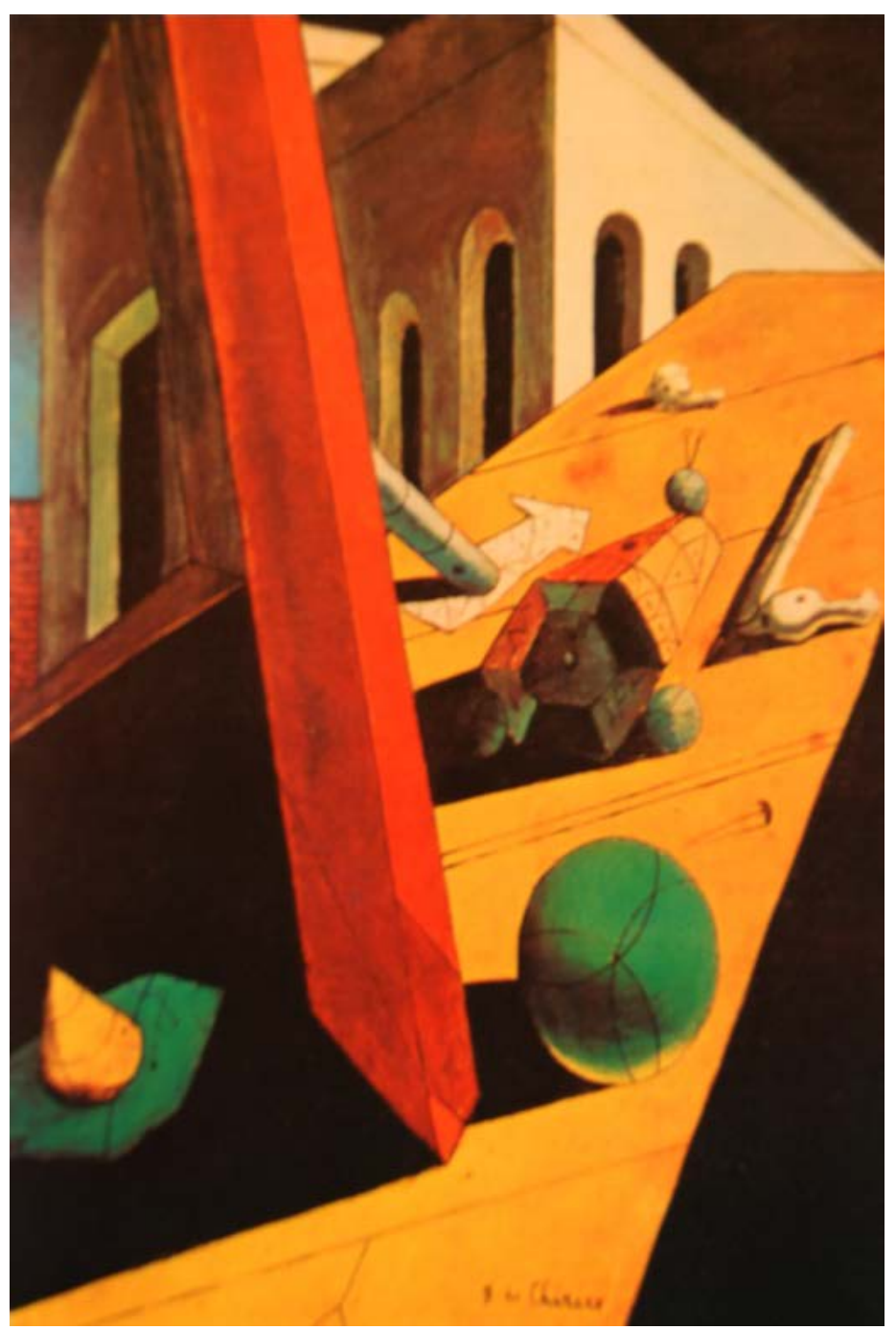

El mal genio de un rey, Giorgio de Chirico (1914) 
Los objetos que representa el pintor italiano, al menos en su primera etapa, aparecen recortados, tratados de forma esquemática, de lo que deducimos que su interés apunta más hacia lo simbólico que hacia lo real. La perspectiva renacentista se ve transformada y alterada con varios puntos de fuga, e introduce en el paisaje elementos de la modernidad, tales como locomotoras, chimeneas o fábricas. De Chirico afirma en sus Meditaciones de un pintor (1911-1912) que la meta de la pintura es la misma que la de la poesía, la música y la filosofía. Ello porque todas deberían ofrecer al público un tipo de sensibilidad distinta que, en el caso de la pintura, tendría que traducirse en la capacidad de impactar nuestros sentidos, conmovernos, porque si el arte se ha de entender como algo que suscita en nosotros sensaciones, entonces se opone a la racionalización y conceptualización de la mirada. De Chirico crítica así el academicismo y aboga por una experiencia del mundo que puede resultar incluso alienadora.

El pintor metafísico nos invita a entender el mundo bajo dos puntos de vista, el de la mayoría y el de los individuos con capacidades clarividentes que pueden percibir espectros, sombras y apariencias. De ahí que, en su pintura, se observe cierta obsesión por despertar en el espectador una sensación de extrañeza, nostalgia, presagio o melancolía.

Una característica importante de la corriente que representa Chirico es el deseo de encontrar novedad en lo que es aprehendido por la percepción visual, lo cual constituye una propiedad sin precedentes para la denominada modernidad. Por otra parte, en su pintura, la mezcla de elementos arquitectónicos clásicos, con paisajes y objetos contemporáneos constituye una encrucijada cultural que apunta hacia la pérdida de identidad del hombre moderno, quien se ve relegado en pos de la nueva tecnología y de la máquina. Esa desidentificación habla de una de las principales características del siglo XX, y tal vez sea la explicación de por qué en la obra del pintor italiano se observa, a partir de 1920, la recreación nostálgica de un pasado perdido, en el cual el hombre vivía en equilibrio con el cosmos, de tal manera que la figura humana, lejos de aparecer desproporcionada y enigmática, aparece con todo su esplendor y presencia.

La pintura surrealista abre un nuevo tipo de relación entre la obra y el espectador, pues no se trata ya de reconocer a primera vista lo que sucede en la obra, sino de penetrar en lo desconocido, dejando a la técnica únicamente el papel de servir a los objetivos del cuadro. Esa vinculación permite hablar de una actitud por parte del espectador que desvela la vida secreta de lo que tiene lugar en la pintura, interiorización que, como ya habíamos dicho, transforma la ventana albertiana en el sentido de desprenderse de todo aquello que atañe al mundo exterior. Dicha transformación ha tenido lugar a lo largo del siglo XIX y principios del siglo XX, y representa el enfoque de una nueva forma de ver que ha constituido uno de los cimientos de nuestra contemporaneidad, dando paso a la posmodernidad.

\section{DE LA NATURALEZA A LA ABSTRACCIÓN, UNA MIRADA DISTANCIADA}

Para hablar de la percepción entendida desde el recuerdo, hemos recurrido a la revisión de la obra pictórica de Zoran Music y al comportamiento que ante esta disciplina adopta William De Kooning, pintores para los cuales la conciencia del que observa es tan importante como la propia representación, lo cual nos permite situar la subjetividad 
del artista como determinante número uno, además de tener en cuenta cómo funciona nuestra memoria. Ya sea a modo de archivo, ya de almacenaje personal de imágenes, nos cuestionamos cuál ha sido el proceso de almacenamiento y cómo el recuerdo transforma o modifica aquello visualmente percibido.

Resulta casi humillante hablar de percepción en la obra de un pintor como Zoran $\mathrm{Mu}$ sic, quien, después de 25 años de terminada la Segunda Guerra Mundial retoma desde el propio recuerdo, casi con «la imposibilidad de substraerse, de liberarse, de olvidarse de todo aquello, la necesidad ineludible de volver allí una y otra vez, de purgar una memoria ya por siempre mancillada, estigmatizada» (Zoran Music. De Dechau a Venecia, 46).

Podríamos calificar a Music como pintor de una memoria colectiva, aunque más que testimoniar la muerte con la que convivió a diario en los campos de concentración de Dechau, nos ofrece una representación del ser humano enaltecida hasta el punto de ser una de las más importantes de la segunda mitad de siglo XX. Aun y a pesar de la barbarie absurda pero cruel hasta el límite, Music, según sus propias palabras, mantenía la capacidad de distanciarse de aquello que veía, aspecto que quizás le permitió captar de ese mundo el poder sin razón y la sin importancia de aplastar al ser humano fuera de cualquier límite. Dibujaba a escondidas un montón de cadáveres, al igual que hubiera hecho con un paisaje o un bodegón: «De una cosa que ves cada día, que miras cada día, que ves siempre..., en un momento determinado, ya no te das cuenta, ya no la ves [...]» (Zoran Music. De Dechau a Venecia, 55).

Zoran Music pinta años después, y desde su recuerdo, un tipo de figuración de alto potencial expresivo. Sus pinturas manifiestan una contención gestual y cromática que habla de la monotonía y aislamiento sufridos, al tiempo que revela sus referentes históricos: Goya y Giacometti, sobre todo por la forma de representar las cabezas, los huecos de los ojos, las fosas nasales y la boca. En palabras de Valeriano Bozal,

Music se pinta a sí mismo como un profeta, un profeta del pasado y como un muerto en vida: uno de aquellos cretinos (Dechau) o musulmanes (Auschwitz) que él rescató en su serie «No somos los últimos» [...] Si había alguna escapatoria, era ésta, acabar fundiéndose y confundiéndose con aquellos muertos para poder darles alguna forma de vida; haberse convertido en uno de ellos desde el presente de la supervivencia y, sobre todo, desde la sabiduría de una vida íntegramente entregada a la pintura (cit. en Zoran Music. De Dechau a Venecia, 47).

Recuerdos, vivencias por supuesto inolvidables que más tarde, en los años en que Zoran pinta paisajes de Siena, reviven con la persistencia de un presente. Según sus propias palabras: "Ver las cosas de otra forma». Si primero montones de huesos humanos parecían a su mirada montañas blanquecinas, ahora los paisajes alrededor de Siena toman la apariencia de cadáveres desnudos. El recuerdo cambia y deforma cualquier imagen, hasta el punto de devenir una cosa distinta a la de origen. 


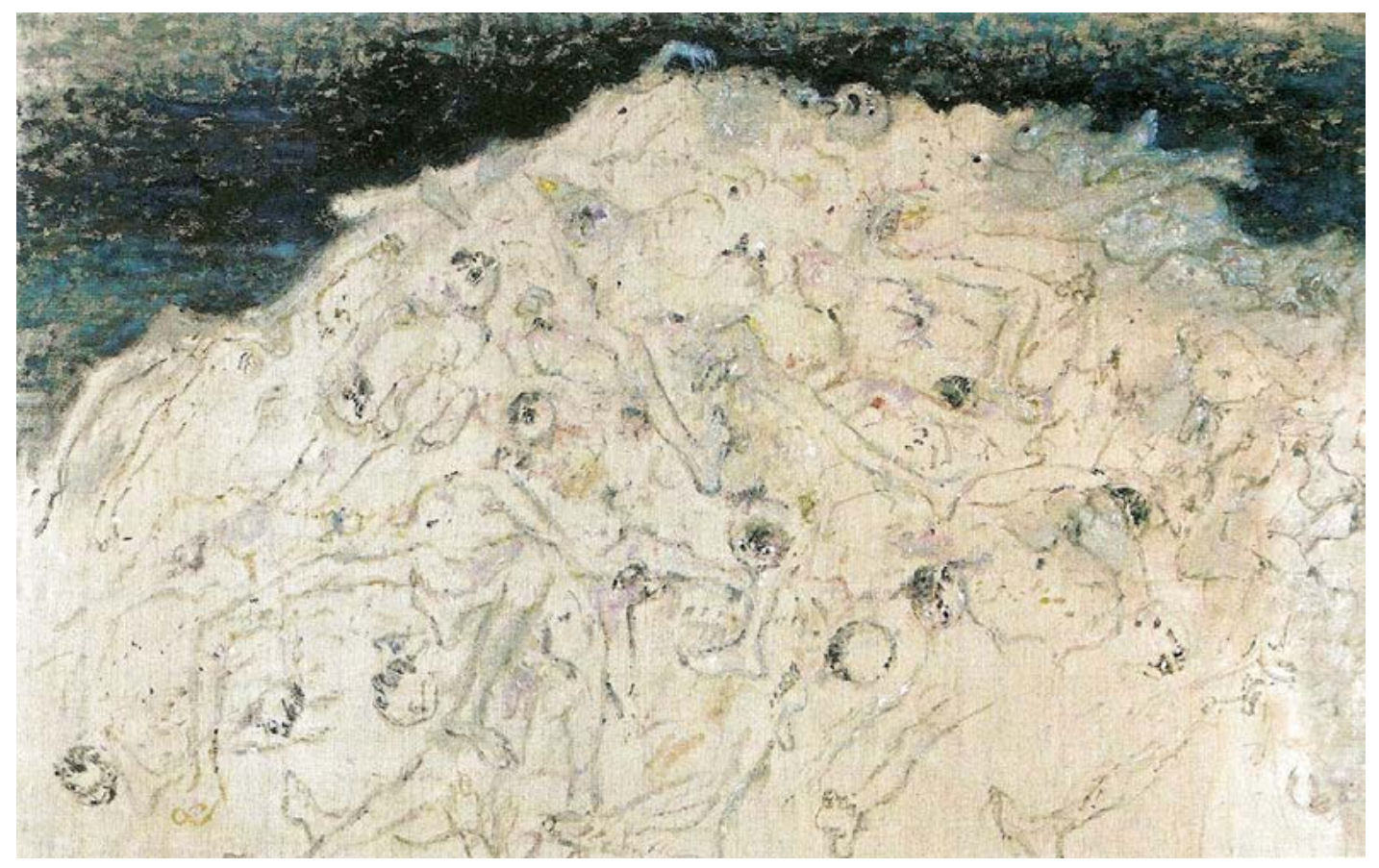

No somos los últimos, Zoran Music (1973)

Desde esa perspectiva podemos entender al propio pintor cuando nos dice que el tema de su obra a lo largo de toda su vida ha sido el mismo, esto es, un paisaje desértico.

En su pintura la subjetividad o su recuerdo son los protagonistas. La obra camina hacia la abstracción, gracias a la distancia respecto de la realidad, que abre paso a la fragmentación y a un tipo de factura representativa, en la cual el espectador tiene un espacio propio para la interpretación. Cabe hablar también de imaginación en un tipo de percepción como el que describimos, en el cual, si bien hay un punto de partida que supone una contemplación de lo real, hablar de recuerdo es algo que únicamente a nosotros nos pertenece. Preguntarnos por cómo actúa el recuerdo sobre nuestra obra supone reflexionar sobre la diversidad de sensaciones y reflexiones que ello nos produce en contraste con el momento actual. Comparablemente, nos podemos cuestionar cuál es nuestra sensación cuando recordamos cómo hemos elaborado una obra y cómo la vemos una vez acabada. Es como si nuestro ser y nuestro parecer entraran en cierto grado de contradicción.

Más allá de lo expuesto, pensar en nuestro pasado y en cómo hemos hecho tal o cual pintura supone acercarnos a la idea de autor de una obra, aun tratándose de la nuestra propia. El recuerdo de nuestro trabajo, tentativas, desciframientos o iluminaciones que hacen que nos decantemos por una solución y no por otra, supone hablar de una agrupación de formas, colores y composiciones que han dado lugar a que la obra sea la que es, y todo ello según un conjunto de decisiones tomadas por una fuerza interior un tanto desconocida, incluso tal vez con una voluntad de existencia en contra de nuestra propia libertad. De ello podemos deducir cómo el «autor» o la noción del «yo» nos lleva fuera de nosotros mismos y también a hablar del «otro». Dudamos muchas veces precisamente de una obra nacida espontáneamente o por azar, a pesar de la excelencia de sus cualidades y su capacidad de seducción. Ello puede no ser más que otra prueba de la difícil tarea 
de considerar quién es el autor, dificultad a la que nos hemos referido en el comentario sobre la pintura de Zoran Music. Porque, si bien dicho quehacer artístico no es exclusivo de este autor, sí es representativo, dadas las especiales circunstancias que vivió. La idea o noción de un «yo» que está fuera de nosotros mismos se desarrolló de forma considerable durante la segunda mitad del pasado siglo.

\section{PERCEPCIÓN SINESTÉSICA: WILLIAM DE KOONING}

La percepción entendida no sólo desde el recuerdo, sino como aquella capacidad del ser humano que cae fuera de su propia voluntad, es uno de los planteamientos que sugiere la pintura de William de Kooning: llegar hasta el inconsciente a través de una percepción que incumbe a la totalidad de nuestro cuerpo.

Si bien el contacto con el natural y su observación son dos cosas que comparten Zoran Music y William de Kooning, la pintura del último se distingue precisamente por prestar atención no solamente al sentido de la vista sino también a la medida en que el resto del campo sensorial del ser humano está presente en aquello que representamos. Ese aspecto nos conduce a un nuevo tipo de percepción: la sinestesia, entendida como la capacidad del ser humano de percibir sensaciones a través de todos los sentidos. Si bien otros pintores antes que De Kooning, ya en los años en que emergieron las primeras vanguardias, reflexionaron acerca de la sinestesia, sólo recientemente ha dejado de ser un aspecto subordinado a otros.

Trabajar con los ojos cerrados o viendo la televisión fueron dos técnicas que William de Kooning practicó de forma fehaciente, con la intención de independizar el ojo (sentido que en nuestra cultura, la occidental, es considerado el más noble), del sentido del tacto. Por otra parte, con ello el pintor pretende aislar cualquier anécdota que pudiera distraer aquel primer contacto que el natural le había proporcionado de modo casi virgen. De esa forma, el recuerdo está presente en la pintura de De Kooning, aunque el resultado del procedimiento empleado nos deja entender que le importa poco o nada su parecido con el natural.

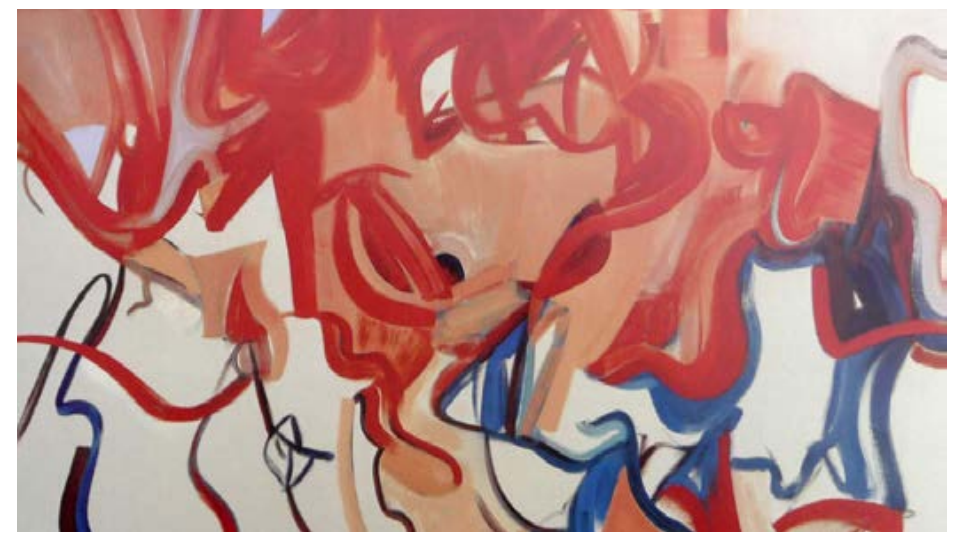

Sin título, William de Kooning (1988) 
Trabajar con los ojos cerrados suponía para el pintor neerlandés, que creó desde el otro lado del Atlántico, aislarse de todo tipo de imagen preconcebida y enaltecer precisamente el sentido del tacto. Así, lejos de cualquier tipo de subordinación sensorial, sus dibujos son exagerados, a veces deformes, pero precisamente ese aspecto permite aumentar la conciencia de quien los realiza y cómo las proporciones cambiantes intensifican la gestualidad de lo representado. Él mismo en ocasiones habla de estar sorprendido ante los resultados obtenidos, pues a pesar de poseer una imagen mental, el hecho de ejecutar un dibujo con los ojos cerrados supone arriesgarse y confiar más en el tacto que en la vista. De Kooning emplea una línea flexible y multidireccional que se introduce casi a modo de cuñas en el espacio que tiene disponible, de modo que sus dibujos se vuelven, a la vez, incoherentes e incomprensibles, lo cual no resta vitalidad a sus figuras; antes bien, se vuelven más energéticas y vitales. Los dibujos así realizados se han calificado como figuras flotantes. Podemos preguntarnos si es la calidad de flotar un modo de percibir las cosas. ¿Es el hecho de que todo flote un intento de liberarse de la imagen o tal vez de sí mismo?, ¿por qué ese interés por crear ambigüedad?, ¿para qué desafiar las leyes compositivas que han regido tantos años el espacio pictórico de la cultura occidental? De Kooning reivindica más que el dibujo de figura, la propia línea. Su línea puede crear tensiones y provocar sensaciones distintas, es más, su significado depende en gran parte de la respuesta que provoca en el espectador.

Privilegiar el dibujo con los ojos cerrados y hasta con la mano izquierda son procedimientos que emplea para favorecer un tipo de percepción sinestésica, esto es, que sin ningún tipo de ordenación preestablecida, todas las sensaciones que recibe nuestro cuerpo son igual de importantes.

\section{PERCEPCIÓN VISUAL Y TECNOLOGÍA}

Sabemos que desde que la fotografía existe, condicionó y cambió la mirada de los pintores. La visualidad del observador después de la aparición de ella se reorganiza, deja de ser algo fijo para convertirse en móvil e incluso intercambiable, con lo cual tenemos que hablar de una nueva valoración de la experiencia visual. Si bien nos toca ahora analizar cómo esta experiencia óptica y sensorial afecta a la pintura del siglo XX, nos cuestionamos, ¿qué códigos nuevos se van a introducir? y ¿cuál es la nueva reorganización espacial a la que asistimos en el campo de la pintura? No podemos obviar que emerge en la segunda mitad de siglo XX una pluralidad de medios técnicos que provoca una modificación de la actividad del ojo y que como consecuencia genera una nueva atención visual.

Según lo cual, atenderemos a la revisión que en ese aspecto nos aporta la obra de David Hockney y Gerhard Richter.

De David Hockney sabemos hasta qué punto empleó la máquina fotográfica para experimentar precisamente otras formas de ver, faceta que podría resumir el conjunto de una obra prolífica e interesante en cuanto a la experimentación, por todas las tensiones conceptuales inherentes al continuo diálogo que establece entre el ojo y el uso de las nuevas tecnologías. Hockney nos plantea metafóricamente de cuántas formas distintas es posible mirar, reflexión que observamos en el conjunto de su obra, si bien para el estudio que nos proponemos resulta adecuado recordar el ensayo sobre ese tema que acompañó 
al catálogo de una exposición suya realizada en la National Gallery y que tituló precisamente «El ojo del artista».

En ese ensayo, el artista plantea cómo distintos tipos de movimiento de nuestros ojos nos ofrecen distintas percepciones. Distintas formas de mirar explican el mundo de distintas maneras, por lo que cabe preguntarse cuál es la percepción de una imagen a través de la máquina fotográfica. El texto cuestiona también las ventajas y desventajas de la reproducción de cuadros: ¿cambia nuestra forma de mirar respecto del original? Las relaciones entre la fotografía y la pintura comparten y divergen en aspectos que hoy por hoy no podemos dejar de lado, dada la evidencia de ellas en nuestra sociedad.

El artista explica que la fotografía es una fuente extraordinaria de placer y que ésa es la razón de por qué nos gusta ver pintura. Curiosa manera de relacionar ambas artes, pero ciertamente que todos habremos experimentado algo parecido cuando contemplamos una reproducción de un cuadro que conocemos bastante bien. Aunque sea un tanto mala o insuficiente, seguramente sentiremos el mismo placer que cuando vimos el original, lo cual significa que experimentamos las mismas vibraciones.

La fotografía nos da la posibilidad de ver en un instante todo lo que hay en una superficie. De hecho, dada su naturaleza bidimensional, podríamos pensar que la única fotografía auténtica es la que nos da una imagen de otra imagen: una reproducción. Al respecto, el poeta inglés George Herbert nos dice: «Cuando un hombre mira un cristal puede posar en él sus ojos o, si lo desea, traspasarlo y espiar entonces el cielo» (cit. en The Artist's Eye's, 163).

Esta formulación nos permite reflexionar acerca de nuestra capacidad de elegir dónde mirar. Detenernos en una superficie o traspasarla. Es evidente que una pintura, una imagen que observamos del natural, es una pantalla, una superficie que nuestros sentidos no pueden atravesar, pero que sí puede atravesar nuestra imaginación, lo que nos lleva a indagar en la diferencia que hay entre una mirada fotográfica y otra distinta, como la del dibujo y la de la pintura.

Para ejemplificarlo, Hockney nos habla del placer que puede producir el contemplar o pintar una sombra, mientras que nombrarla con palabras se aleja bastante de la sensación visualizada. Una sombra no es más que un contorno, algo parecido a lo que nos daría una fotografía, a la cual le faltan muchas cosas para que nuestra experiencia sea total, aspecto que explicaría por qué muchas veces una fotografía no nos da como resultado aquello que tanto nos gustó de la realidad, ya sea de un paisaje, un rostro o un objeto, mientras que el dibujo y la pintura sí podrían entregarlo.

A esa capacidad de engaño que tiene la fotografía se refiere el pintor cuando habla de un determinado evento deportivo. La fascinación que sentimos cuando vemos la imagen de un hombre que está totalmente suspendido en el aire en el momento de dar un salto evidentemente no es perceptible para el ojo humano; si bien podemos ser conscientes de una continuidad en el tiempo mientras eso sucede, no podemos verlo, sí tal vez sentirlo.

David Hockney da esos argumentos para recapacitar sobre las habilidades que parece que hoy en día están quedando marginadas y que él mismo dice defender, ya que, si bien la tecnología es un punto de partida para nuevas investigaciones, no puede sustituir nuestra percepción e identidad personal. La máquina de fotografiar es una herramienta para nuestro trabajo, no una solución.

Un punto de vista distinto es el que nos presenta Gerhard Richter. Si el primero hace uso de la tecnología para ver de otra forma, para experimentar y transformar el espacio pictórico, el segundo convierte la máquina fotográfica en una herramienta que hace 
posible, antes que cualquier otra cosa, testimoniar unas vivencias que después el artista transformará en material apto para ser alterado o convenientemente cambiado y convertido en obra artística que lo identifique. Delante del trabajo del artista alemán, la máquina fotográfica es un punto de partida que no se puede obviar, porque es imprescindible para la contemplación. Si bien ambos artistas conceden a lo visual el punto de origen para su pintura, ambos también hacen uso de la fotografía como ente que dialoga con la primera. Analizaremos a continuación algunas divergencias entre ellos ante el uso de la tecnología. Es de notar la distancia cultural que los separa (a pesar de la similitud cronológica que guardan sus biografías), aspecto que nos habla de la importancia del contexto histórico en el cual se desarrolla cada identidad artística. David Hockney: Bradford, Inglaterra, 1937; G. Richter: Dresde, Alemania, 1932.

Gerhard Richter registra fotográficamente sus vivencias en la Alemania del Este, reproducciones que más tarde recuperará y ampliará desde la otra orilla de su país. Un ejemplo de ello es el archivo o colección de imágenes que dará cuerpo a una de sus obras más importantes, Atlas. La fotografía es empleada aquí a modo de documento, y si bien da fe de la realidad con la precisión propia de la tecnología, Richter la empleará justamente para olvidar y objetivar a esta última.

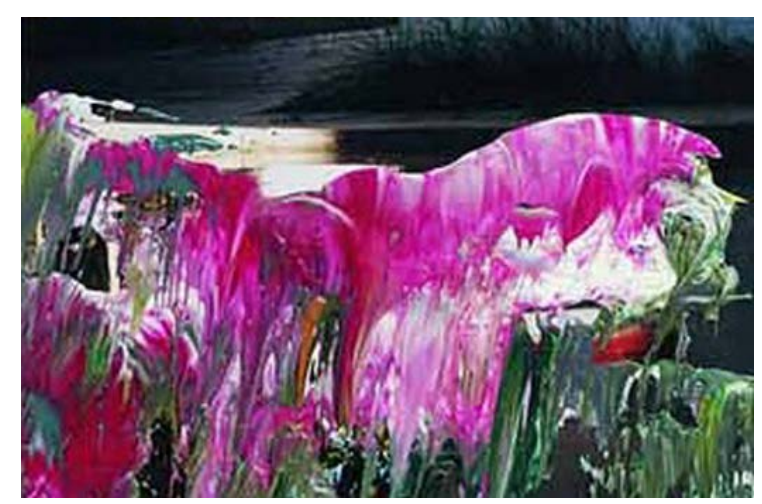

Fotografía pintada, Gerhard Richter (1989)

Comprender a este artista requiere situarlo históricamente en la realidad que vivió: la Alemania que en los años que sucedieron a la Segunda Guerra Mundial se encontraba sumida en un ambiente casi esquizofrénico, dividida en dos: la Alemania Oriental, que, bajo un estilismo real-socialista, había anulado el legado cultural de las primeras vanguardias y donde las obras del expresionismo de los años 60 sólo se mostraban acompañadas de textos marxistas con intenciones de propaganda; y la Alemania Occidental, un territorio en el cual el miedo era la clave para entender a una sociedad que antes que nada quería olvidar, y que vivía casi forzadamente en un clima de amnesia, que imposibilitaba un compromiso intelectual como el que había vivido el mismo país años antes con las acciones del grupo Dada, por ejemplo, o con la obra de K. Schwitters entre otros.

Gerhard Richter se planteaba cómo partir de cero, cómo empezar de nuevo en un país que asociaba la figuración al grupo comunista y la abstracción gestual a un estatus 
de libertad. Esas dudas testimonian una situación social que, si bien se quería olvidar, condicionó la obra de un artista comprometido como el que estudiamos.

Ver, fotografiar y pintar ha sido el proceso artístico que ha empleado este artista, casi a modo de catalizador, para olvidar y también como método para desarrollar su prolífica y exquisita obra. El cuadro para Gerhard Richter no es más que un objeto que manipula. Primero se trata de encontrar, segundo de aceptar y tercero de cambiar o destruir. El pintor nos dice que, a pesar de su carácter de apariencia, la tela pintada está más cerca de la realidad que la fotografía, sencillamente por la materialidad física que la caracteriza. Es precisamente la parte artesanal la que convierte una obra en real, mientras que lo que nos muestra la tecnología es ficción.

Richter emplea la fotografía para objetivar la realidad, incluso corregirla, tratando así de evitar una visión subjetiva y personal. Cuando pinto una fotografía, explica, puedo olvidar el mundo de referencias de donde procedió. Es una manera de olvidar también mi voluntad y de que ella se imponga por encima de la imagen.

La intención de Richter no es pintar una fotografía, como muchos de sus coetáneos, sino alterarla, provocando en parte a la propia tecnología, desenfocando o moviendo la imagen y, aunque ello sea paradójico, alejándose también de la pintura.

Precisamente en su Atlas, selecciona imágenes sin contenido ideológico vanguardista. Busca un arte que podríamos llamar desideologizado, que no trate de problemas sociales. Richter intenta que su obra sea sólo una reflexión sobre las posibilidades que le ofrece el medio pictórico, incluyendo la duda sobre su propia validez, lo cual nos sitúa en las coordenadas de un pintor existencialista por naturaleza.

Tanto David Hockney como Gerhard Richter emplean la tecnología casi hasta la saciedad, hasta hacer que su obra sea distinta y con unas características que la identifican en unas coordenadas espacio-temporales. No obstante, concluimos que la importancia de lo visual y la materialidad del medio son dos aspectos connaturales a la pintura de todos los siglos, tal como la duda y la vulnerabilidad son inseparables de la naturaleza del ser humano. Las formas y las herramientas cambian con la capacidad de situarnos en una cronología que nos define de algún modo, pero lo esencial en la pintura permanece.

\section{CONCLUSIONES}

Preguntarnos por cómo vemos, cómo ha sido la historia de lo percibido en nuestra cultura occidental es casi acercarnos a las formas de representación que han dado lugar a la historia del arte que conocemos. La visión y sus efectos nos hablan siempre de las posibilidades de un sujeto observador, producto, a su vez, de las coordenadas geográficas y temporales que identifica. A modo de resumen, damos respuesta a las preguntas que planteamos en el presente artículo en relación con los textos revisados desde la época impresionista hasta hoy día.

¿Cómo vemos una obra pictórica?, ¿cuál es la actitud del artista y del espectador? Tal análisis puede ser útil para la lectura de una obra de arte que es fruto de una identidad histórica, de un comportamiento artístico, pero sobre todo fruto de una forma particular de «ver».

\section{Mirada impresionista}

1- Obra pictórica: se traduce en subjetividad, aguadas y empastes de color a la vez que una pincelada fragmentada. 
2- Actitud del artista: se sitúa delante del natural, éste es la única verdad que reconoce, y el «ver» es el tema del cuadro.

3- Actitud del espectador: adopta la misma actitud que la del artista que hizo posible la obra.

\section{Mirada racional}

1- Obra pictórica: su pintura es sinónimo de construcción. Las estructuras son los elementos de que se sirve el artista para interpretar la naturaleza.

2- Actitud del artista: contrariamente a los impresionistas, los cubistas revalorizan las facultades intuitivas y autónomas de la inteligencia especulativa. El artista ve y pinta lo que hay en las tres dimensiones del espacio, lo cual implica la intervención del tiempo y de la velocidad. Se abre camino a la autonomía del artista.

3- Actitud del espectador: recorre con su mirada el cuadro, barrido de la imagen que no supone una dirección preestablecida, pudiéndolo hacer desde cualquier punto de partida. Camino abierto hacia la autonomía interpretativa del espectador.

\section{Mirada surrealista}

1- Obra pictórica: ofrece una visión onírica de la realidad, provocación del mundo inteligible que abre camino a las profundidades del ser humano. Su pintura es una invitación a la representación del interior de los seres y las cosas.

2- Actitud del artista: descoloca nuestra forma habitual de ver. Dirige su mirada hacia el interior del individuo. Pinta lo que no se ve, el mundo de los sueños y el de las apariencias, desde donde el artista quiere cambiar y transformar el mundo.

3- Actitud del espectador: su visión tiene que adaptarse a un nuevo sistema de relaciones y esquemas, los cuales sobrepasan el mundo racional. Su libertad y subjetividad se corresponden con la pérdida de identidad del hombre moderno. Se abre camino de la modernidad a la posmodernidad.

\section{Mirada distanciada}

1- Obra pictórica: representa no aquello visto, sino su transformación por medio del recuerdo y la memoria, ya sea personal o colectiva, lo que se traduce en un tipo de pintura que camina de la naturaleza a la abstracción.

2- Actitud del artista: fuera del ámbito de su propia voluntad, adquiere importancia la totalidad del campo sensorial del ser humano. Más allá de la percepción visual, encontramos interés por la representación del inconsciente y de la subjetividad como una forma de encontrar distanciamiento respecto de uno mismo.

3- Actitud del espectador: la autonomía concedida al artista se transfiere también al espectador, quien se cuestiona desde ese punto de vista por la figura del «autor» y por la noción de un «yo» que, fuera de nosotros mismos, nos lleva a hablar del «otro».

\section{Percepción visual y tecnología}

1- Obra pictórica: interviene la fotografía y la imagen digital, con lo cual el espacio pictórico se reorganiza y pasa de ser fijo a ser móvil. Atrás quedan las barreras que separaban una disciplina de otra, para obtener una obra híbrida de difícil clasificación.

2- Actitud del artista: la tecnología provoca ver de otra forma, el mundo se observa a través de una imagen formada por millones de bits que nos ofrece una máquina. Distintos movimientos de nuestros ojos perciben la naturaleza de forma distinta. 
3- Actitud del espectador: espectador y autor forman parte de una misma interfaz. La imagen se desmaterializa y procede también una desidentificación del ser humano, quien forma parte de un sistema de comunicación en el cual prima el intercambio y la interactividad.

Estos elementos de juicio nos permiten hablar de la encrucijada temporal en la cual hoy día nos encontramos: una visualidad que pertenece a lo cibernético, en donde elementos visuales, abstractos y lingüísticos coinciden y pueden ser globalmente intercambiados. Preguntarnos por el modelo de percepción que sigue nuestra generación supone hablar de ruptura o bien de continuidad, pero que en todos los casos hemos de afrontar con el conocimiento de las bases que nos preceden y aceptando la incertidumbre del futuro.

\section{REFERENCIAS}

Bauman, Zygmunt. Arte, ¿̇líquido? Madrid: Ediciones Sequitur, 2007. Medio impreso.

Crary, Jonathan. Las técnicas del observador. Visión y modernidad en el s. XIX. Murcia: Cendeac, 1990. Medio impreso.

Deleuze, Gilles. A Thousand Plateaus. Trad. Brian Massumi. Mineápolis: University of Minnesota Press, 1987. Medio impreso.

Doran, M. Sobre Cézanne. Barcelona: Ed. Gustavo Gili, 1980. Medio impreso.

Gerhard Richter [Catálogo de exposición]. Madrid: Ed. Centro de Arte Reina Sofía, 1994. Medio impreso.

Hockney, David. Así lo veo yo. Madrid: Ed. Siruela, 1994. Medio impreso.

Kahnweiler, D. H. Juan Gris. Vida, Obras y Escritos. Barcelona: Quaderns Crema, 1995. Medio impreso.

Lambán, J. y P. Pascal Torres, No se puede mirar Goya, Zoran Music, Resnais, Alain. Zaragoza: Diputación Provincial. Consorcio Cultural Goya-Fuendetodos, 2007. Medio impreso.

Rubio, Oliva María. La mirada interior. Madrid: Editorial Tecnos, 1994. Medio impreso.

Stoichita, Victor I. Ver y no ver. Madrid: Ediciones Siruela, 2005. Medio impreso.

The Artist's Eye's [catálogo de exposición]. London: Nacional Gallery, 1981. Medio impreso.

Valsecchi, Marco. «Introducción». Georges Braque. La obra pictórica completa de Braque: de la Descomposición Cubista a la Recuperación del Objeto. Barcelona: Ed. Noguer, 1976. Medio impreso.

William de Kooning [Catálogo de exposición]. Valencia: Institut Valencià d'Art Modern. IVAM, 2001. Medio impreso.

Zola, Émile. «L'Écran». Correspondance. Paris-Montreal: Ed. B. H. Bakker, 1979. Medio impreso.

Zoran Music. De Dechau a Venecia [catálogo de exposición]. Barcelona: Fundació Caixa de Catalunya, 2008. Medio impreso.

Recepción: 7 de junio de 2010

Aceptación: 20 de octubre de 2010 